MR. JOSHUA A. THIA (Orcid ID : 0000-0001-9084-0959)

PROF. PIERRE-MICHEL FORGET (Orcid ID : 0000-0002-9252-974X)

Article type : Paper

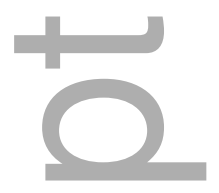

$\square$

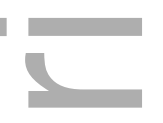

LRH: Aliyu et al.

RRH: Conditional Seed Dispersal Mutualisms

\title{
Forest disturbance and seasonal food availability influence a conditional seed dispersal mutualism
}

Babale Aliyu ${ }^{1}$, Joshua A. Thia ${ }^{2,7}$, Elena Moltchanova ${ }^{3}$, Pierre-Michel Forget ${ }^{4}$, and Hazel M. Chapman $5,6,7$

${ }^{1}$ Department of Biological Sciences, Gombe State University, Tudan Wada Street, Gombe, Gombe State, Nigeria

${ }^{2}$ School of Biological Sciences, The University of Queensland, Brisbane, QLD 4072, Australia

${ }^{3}$ School of Mathematics and Statistics, University of Canterbury, PB 4800, Christchurch, New Zealand

${ }^{4}$ UMR 7179 MECADEV CNRS-MNHN, Département Adaptations du vivant, Muséum National d'Histoire Naturelle, 1 avenue du Petit Château, 91800, Brunoy, France

${ }^{5}$ School of Biological Sciences, University of Canterbury, PB 4800, Christchurch, New Zealand ${ }^{6}$ Nigerian Montane Forest Project, Yelwa Village, Taraba State, Nigeria

${ }^{7}$ Corresponding authors; e-mail: josh.thia@live.com and hazel.chapman@ canterbury.ac.nz Received 2 July 2017; revision accepted 16 April 2018.

This is the author manuscript accepted for publication and has undergone full peer review but has not been through the copyediting, typesetting, pagination and proofreading process, which may lead to differences between this version and the Version of Record. Please cite this article as doi: 10.1111/btp.12570

This article is protected by copyright. All rights reserved 


\section{ABSTRACT}

The interaction between granivorous scatter-hoarding mammals and plants is a conditional mutualism: scatter-hoarders consume seeds (acting as predators), but the movement of seed by scatter-hoarders may contribute to dispersal (acting as mutualists). Understanding the ecological factors that shape this relationship is highly relevant in anthropogenically disturbed tropical forests where large-bodied frugivores are extirpated. In such forests, large-seeded trees that once depended on these frugivores for dispersal may now only have scatter-hoarders as prospective dispersers. We studied Carapa oreophila (Meliaceae) in an Afromontane forest, to test the hypotheses that the proportion of seeds immediately consumed or hoarded (dispersed) would vary over a disturbance gradient. Temporal replication also afforded exploration of how habitat effects might vary with food availability. Using a Bayesian framework, we demonstrate that seeds were more likely to be hoarded in less disturbed forest, irrespective of temporal variation in food abundance. In contrast, forest disturbance only appeared to increase seed predation in temporal replicates that coincided with sustained food availability. These results highlight the potential variability in the dynamics between plants and scatter-hoarders over fine temporal scales, elucidating possible ecological scenarios where scatter-hoarders might act as mutualists (contributing positively to plant recruitment). Our study also fills important knowledge gaps about the importance of scatterhoarders as dispersers in tropical forests depleted of large-bodied frugivores, particularly in Africa where scatter-hoarding mutualisms have not been extensively studied.

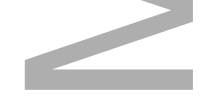

Key words: Afrotropics; Carapa oreophila; granivorous scatter-hoarding mammals; large-seeded trees; Nigeria; plant-animal interactions; seed dispersal; tropical montane forests.

\section{SCATTER-HOARDING, WHEREBY SEEDS ARE COLLECTED FROM THE FOREST FLOOR AND DEPOSITED IN} SHALLOW CACHES, is a common behavior among rodents as a means of exploiting seasonal food abundance (Vander Wall et al. 2005, Forget et al. 2002). While the purpose of scatter-hoarding to the mammal is for consumption of seeds at a later date (when resources are scarce), seeds in forgotten caches may escape being eaten and establish as seedlings (Jansen et al. 2012). Such seeds potentially receive two major benefits over seeds deposited directly onto the forest floor. Firstly, cached seeds may be in a more suitable germination environment, which will increase the probability of seedling establishment (Vander Wall 2010, Hirsch et al. 2012). Secondly, scatterhoarders may act as secondary dispersers of seeds, moving them beyond the destinations achieved by primary modes of dispersal, for example, gravity or frugivorous animals (Forget et al. 1998, Brewer 2001). 
On discovery of seeds, the decision made by scatter-hoarding rodents to either immediately consume them, remove them to another site and immediately consume them, or remove them to another site and store them for later consumption, is ecologically contingent (Augaasen et al. 2010, Vander Wall \& Beck 2012, Wang et al. 2013). Seed characteristics and abundance influence behavior. Highly nutritious and palatable seeds are more likely to be targets of immediate consumption than seeds that provide low nutrient value, are unpalatable, or difficult to handle (Wang \& Chen 2009, Aliyu et al. 2014, Vander Wall 2010). Moreover, if seed availability is high, a greater proportion of seeds discovered by scatter-hoarders are likely to be hoarded because more seeds are available than are required to satiate the scatter-hoarding community (Vander Wall \& Beck 2012, Augaasen et al. 2010, Jansen et al. 2004). Consequently, the fate of seeds discovered by scatter-hoarding mammals may vary with season (Augaasen et al. 2010). This interaction is mutualistic when the benefit of seed dispersal is outweighed by the cost of seed predation (Theimer 2005), and hence, the ecological contingency of this interaction deems it a conditional mutualism (Theimer 2005, Jorge \& Howe 2009).

Habitat effects may also be important in modulating the conditionality of secondary dispersal mutualisms. In several studies, forest disturbance and degradation have been shown as key drivers in shifting the balance from mutualistic to predatory roles by scatter-hoarding mammals. Jorge and Howe (2009) demonstrated that increasing fragmentation of forests increases seed predation by Neotropical scatter-hoarding mammals because smaller forests have reduced food availability. Forest edges, which are more disturbed than forest interiors, and have different plant composition, may also experience higher ratios of consumption to hoarding and declines in the distance seeds are moved by mammals (Chauvet \& Forget 2005, Forget \& Cuijpers 2008, Aliyu et al. 2014, Forget et al. 1999). However, the impact of disturbance on rodent behavior in regard to the between seed dispersal and consumption varies across plant species (Holl \& Lulow 1997, Aliyu et al. 2014), thus requiring species-specific assessment of how habitat effects modulate conditional scatter-hoarding mutualisms with plants.

The potential benefits of secondary dispersal by scatter-hoarding mammals may be greatest in locales where frugivorous animal dispersal agents have become scarce or locally extirpated (Jansen et al. 2012, Cramer et al. 2007, Babweteera 2009, Babweteera et al. 2007, Babweteera \& Brown 2010, Thia et al. 2016). This is especially true in tropical and sub-tropical forests where largebodied frugivores are often the target of the bush meat trade (Ripple et al. 2016) and are most susceptible to anthropogenically driven habitat disturbance and degradation (Babweteera \& Brown 2010, Thornton et al. 2012). Concurrently, large-seeded trees are highly dependent on large frugivores for dispersal (Cramer et al. 2007, Babweteera 2009, Babweteera et al. 2007); hence, it is 
vital to ascertain how much scatter-hoarders contribute to seed dispersal as this might strongly impact tree recruitment dynamics.

While scatter-hoarding by mammals has been studied extensively in the Neotropics (e.g., Forget 1990, Forget et al. 1999, Jansen et al. 2004, 2012, Forget \& Cuijpers 2008, Pinto et al. 2009, Haugaasen et al. 2010), relatively little is known about scatter-hoarding in Africa. While some recent studies have emerged from African forests (Nyiramana et al. 2011, Aliyu et al. 2014, Rosin \& Poulsen 2017, Moupela et al. 2014), there remain critical gaps in our knowledge about the importance of scatter-hoarders to the recruitment dynamics of African forest trees, not to mention how these dynamics change under different ecological conditions. Addressing these gaps is particularly imperative where anthropogenic disturbance is rapidly changing ecosystems. To this end, we use Carapa oreophila Kenfack sp. nov. (Meliaceae) (Kenfack 2011) as a model to assess the role of granivorous mammals as dispersers of large-seeded Afrotropical trees and to investigate the conditionality of scatter-hoarding behavior in disturbed forests. The big, heavy fruit and seeds of $C$. oreophila suggests that it is adapted to dispersal by very large frugivores (Guimaraes Jr. et al. 2008), possibly elephants (Debroux 1998). However, at our study site, Ngel Nyaki Forest Reserve (Nigeria), elephants have been locally extinct since at least the 1940s (Thia 2014), and we have never observed any primary frugivore dispersers for C. oreophila. We know from personal observations (camera traps) that two species of rodents, the African giant pouched rat (Cricetomys sp.) and the African brush-tailed porcupine (Atherurus africanus), are the major consumers of C. oreophila seeds in Ngel Nyaki forest. Both these rodents are known to scatterhoard and previous studies at Ngel Nyaki (Dutton et al. 2014, Aliyu et al. 2014) and forests elsewhere in Africa (Nyiramana et al. 2011, Rosin \& Poulsen 2017) indicate that they may contribute to dispersal of Carapa and other large-seeded species. All aforementioned ecological features of $C$. oreophila, and the ease of collecting substantial numbers of seeds during peak fruiting season, make it an ideal species to study secondary dispersal by scatter-hoarding rodents. We investigated how the immediate fates of the large nutrient rich C. oreophila seeds were influenced by forest disturbance (habitat: core, edge, or forest fragment) and different periods during the fruiting season (food abundance) at Ngel Nyaki. Our study therefore assesses how different ecological factors interact to influence a scatter-hoarder's initial decision to hoard or consume discovered seeds. At Ngel Nyaki, greater disturbance through anthropogenic effects causes ecological degradation, and the diversity and abundance of large-seeded trees is lower in disturbed forest. We therefore hypothesized that the proportion of seeds hoarded versus consumed would correlate with disturbance; we predicted that increased disturbance from core, to edge, to forest fragment, would show decreasing propensity for rodents to hoard, and an increase in immediate consumption, of $C$. oreophila seeds. Additionally, we considered how habitat effects 
might change with temporal variation in food availability in the forest using phenological records. Our results provide evidence that decisions by rodents to immediately hoard or consume seed might have complex interactions with forest disturbance and temporal patterns of seed abundance.

\section{METHODS}

STUDY SITE. - The study was conducted within Ngel Nyaki Forest Reserve (http://www.canterbury.ac.nz/afromontane/) on the Mambilla Plateau, Taraba State, Nigeria ( $7^{\circ} 5^{\circ} \mathrm{N}$, $\left.11^{\circ} 3^{\mathrm{C}} \mathrm{E}\right)$. The reserve covers a total area of 4600 ha and includes 750 ha of almost continuous midaltitude sub-montane forest at 1400-1600 m elevation (Chapman \& Chapman 2001). This forest is embedded within a grassland landscape of Sporobolus grasses, which have been introduced via cattle and form a largely monoculture matrix (Beck \& Chapman 2008, Adanu et al. 2010). The mean annual rainfall is $1800 \mathrm{~mm}$ (Nigerian Montane Forest Project rainfall data) and the mean monthly maximum and minimum temperatures for the wet and dry seasons are 26 and $13^{\circ} \mathrm{C}$, and 23 and $16^{\circ} \mathrm{C}$, respectively (Matthesius et al. 2011).

Three main habitat types are described in this study, sensu Aliyu et al. (2014): interior core forest (COR), edge forest (EDG; 100m into the main forest from the surrounding grassland), and small forest fragments (FRG) that are embedded in the grassland. Forest fragments are riparian, tightly hugging the borders of streams, and range from a few meters to tens-of-meters across. These habitats exist along a disturbance gradient: core forest is the least disturbed, edge forest is somewhat disturbed, and forest fragments are highly disturbed and degraded. The main causes of degradation to edge and forest fragments are burning of the grassland by local pastoralists and damage caused by cattle. Additionally, the abundance and diversity of large-seeded trees also decreases from core, to edge, to forest fragments (Aliyu 2014), suggesting that forest fragments are poor quality foraging habitats for scatter-hoarding rodents.

STUDY SPECIES. - Carapa oreophila is an endemic tree to Cameroon and the eastern Nigerian highlands (Kenfack 2011). It is distributed in montane regions at elevations ranging from 1100$2500 \mathrm{~m}$ above sea level. Carapa oreophila is common within the main Ngel Nyaki Forest but is less common in the forest fragments. Its fruit are large woody pods (approx. $130 \times 100 \mathrm{~mm}$ ), each containing up to four or five valves that hold about four shiny, smooth, large seeds: $41.38 \pm 4.45$ $\mathrm{mm} \times 29.70 \pm 3.34 \mathrm{~mm} \times 34.33 \pm 3.67 \mathrm{~mm}$ (mean \pm standard deviation for length, width and height, respectively; $N=20$ seeds). These seeds are without pulp and possess a hard seed coat. Such fruit and seed characteristics are adapted for consumption and dispersal by elephants, as evidenced by Carapa species seeds being recovered in elephant dung in Camerounese Dja Reserve, for instance (Debroux 1998: Table 3.3, pg. 84). Elephants, however, are locally extinct at our study site. 
Fruiting of $C$. oreophila is mostly synchronous, with the peak of the fruiting season being towards the end of the rainy season in August, although individual trees can be found fruiting any time of the year (Nigerian Montane Forest Project phenology data, 2006-present). Based on known adult trees $(>10 \mathrm{~cm}$ in diameter at breast height of $1.4 \mathrm{~m})$ in our study area that occur along extensive, monthly-monitored phenology transects, it was estimated that the peak fruiting of $C$. oreophila in 2011 was from August-October (Fig. 1).

EXPERIMENTAL DESIGN.- Our study is concerned with the immediate seed fates of C. oreophila across a forest disturbance gradient (core < edge < fragment) and at different points during the peak fruiting season. Specifically, we recorded if seeds were either: (1) consumed, (2) hoarded (dispersed), or (3) missing.

To test for the effect of forest disturbance (habitat effects), we followed the experimental procedure sensu Aliyu et al. (2014). Two $100 \mathrm{~m}$ long transects (at least $100 \mathrm{~m}$ apart) were placed in each habitat type. A $1 \times 1 \mathrm{~m}^{2}$ quadrat was placed every $25 \mathrm{~m}$, so five quadrats per transect. Each quadrat was divided into four $0.25 \mathrm{~m}^{2}$ plots, where five fresh $C$. oreophila seeds were placed; one in the plot centre and one in each corner. Seeds was tagged with a $1 \mathrm{~m}$ long white nylon thread following the method of Forget (1990). The experiment was replicated in four periods during the fruiting season: August 18-28 (Period 1), September 5-15 (Period 2), 18-28 (Period 3), and October 2-12 (Period 4). Each period lasted 10 days and fresh seeds were used at the start of each new replicate. Based on our fruiting phenology data (Fig. 1), the abundance of C. oreophila producing mature fruit was highest in Period 1 (August), slightly lower in Period 2 and 3 (September), and lowest in Period 4 (October).

In total, we deployed 2400 seeds ( 4 periods $\times 3$ habitats $\times 2$ transects $\times 5$ quadrats $\times 4$ plots $\times 5$ seeds). At 10 days, the end of each experiment, the fates of each seed were determined by searching a $10 \mathrm{~m}$ radius around each quadrat. Consumed seeds were identified by having been partially consumed or by the presence of a loose thread with no seed attached. Hoarded seeds were classed as those that had either been buried under the soil or cached under leaf litter. Missing seeds were those that could not be accounted for in our searches and may have been consumed, hoarded or simply not detected.

STATISTICAL ANALYSES.-We examined the influence of food abundance (temporal replicates: Period 1, 2, 3, and 4) and forest disturbance (habitat effects: COR, EDG and FRG) on the immediate decisions made by scatter-hoarders when encountering seeds. We specifically wanted to understand how a forest degradation gradient affected the proportion of seeds that succumbed to 
different fates. To this end, we tested whether seed consumption was greatest in forest fragments and lowest in core forest, and whether hoarding was greatest in core forest and lowest in fragments. We analyzed our data in a Bayesian framework using a mixed effects multinomial logistic regression model, appropriate for modelling categorical responses (consumed or hoarded) within a hierarchical repeated measures design (Agresti 1986). The seeds within each plot were assumed to have a multinomial distribution with the category-specific probabilities dependent on period (temporal replicate), habitat, transect, quadrat, and plot; for more details refer to Aliyu et al. (2014) where a similar approach was implemented. The results of Bayesian analyses are presented in terms of $P$, posterior probabilities, the probability that a statement is true given the observed data. As $P$ approaches a value of 1.00 there is increasing support for the hypothesis given the data. Rather than being limited to simple pairwise comparisons, a Bayesian approach allows the assignation of a posterior probability to a compound hypothesis, such as $\theta_{1}<\theta_{2}<\theta_{3}$. For example, we use the notation $P(\mathrm{COR}<\mathrm{EDG}<\mathrm{FRG})$ to denote the posterior probability of the hypothesis that seed consumption is lowest in core, intermediate in edge, and greatest in forest fragments. We also tested the hypothesis that hoarding would be greatest in the core, intermediate in edge, and lowest in forest fragments, that is: $P(\mathrm{COR}>\mathrm{EDG}>\mathrm{FRG})$.

All the regression model parameters were given non-informative Gaussian priors. The first 5000 iterations were discarded as a burn-in, and the posterior sample statistics and $95 \%$ Bayesian credible intervals (CIs) were evaluated from the next 5000 iterations. Convergence and mixing were assessed visually. A Deviance Information Criterion (DIC) was employed for model comparison. The smaller values of DIC correspond to better model fit. We used the statistical software package WinBUGS (Spiegelhalter et al. 2002) for our analysis. The software $R$, including the R2WinBUGS package, was used for additional posterior inference and graphs (Sturtz, S., Ligges, U., Gelman 2005, R Core Team 2014).

\section{RESULTS}

Seeds were removed from all plots irrespective of habitat or fruiting period. For any given period in our experiment, by 10 days, most (if not all) seeds had been removed. Of the 2400 C. oreophila seeds deployed, 2384 (99.33\%) were removed and 1566 (65.69\%) were recovered. Of those seeds that were recovered, $890(56.83 \%)$ were consumed, and $676(43.17 \%)$ were hoarded. When averaging across all temporal replicates, we found little evidence for habitat effects on seed fates (Fig. 2A). The hypothesis that seed consumption would be highest in forest fragments and lowest in the core forest was weakly supported by habitat averages: $P(\mathrm{COR}<\mathrm{EDG}<\mathrm{FRG})=$ 0.1983. There was only slightly more support for our hypothesis that average hoarding was greatest in the core forest and lowest in forest fragments: $P(\mathrm{COR}>\mathrm{EDG}>\mathrm{FRG})=0.2535$. We also present 
the average across habitats in each temporal replicate (Fig. 2B). We did not however specifically test any hypotheses regarding differences among periods on habitat-averaged fates because of the interaction between habitats and period (Fig. 3; Table 1). Indeed, it was only when considering each temporal replicate separately that habitat effects became apparent. The hypothesis that seed consumption would increase with forest disturbance (COR $<$ EDG $<$ FRG) was very poorly supported at the start of the fruiting season (Period $1, P=0.0326$ ), and strongly supported in the middle of fruiting season (Period 2 and Period 3, $P>0.9966$ and 0.9089, respectively). By the end of our experiment, consumption rates among habitats was equivalent (Period $4, P=0.1066$ ). In contrast, support for the hypothesis that the proportion of hoarded seeds was greater in less disturbed forest (COR > EDG > FRG) was very well supported in all periods, though there was less support for this at the end of the fruiting season (Period 1, 2, and 3, $P \geq 0.9886,0.9840$, and 0.9800, respectively; Period 4, $P=0.7034)$.

\section{DISCUSSION}

The ability for scatter-hoarding mammals to move large seeds and provide seed dispersal for largeseeded tree species may be increasingly necessary due to the decline of many historical primary dispersers (Jansen et al. 2012, Babweteera et al. 2007, Ripple et al. 2016). However, the role scatter-hoarders play — as antagonistic predators or mutualistic dispersers - is contingent on ecological context. We provide evidence that forest disturbance influences a conditional seed dispersal mutualism between scatter-hoarding mammals and Carapa oreophila in an Afromontane forest system. By comparing the proportion of different seed fates across temporal replicates, our data also suggests that these habitat effects might themselves be reliant on the amount of food available to scatter-hoarding rodents. Together, habitat and fruiting phenology might drive recruitment dynamics of $C$. oreophila at our study site, Ngel Nyaki Forest Reserve (Nigeria).

The proportion of removed $C$. oreophila seed in our study was large, 84.5-100\% across all seasons and plots. Direct comparisons of seed removal rates among secondary seed dispersal studies can be difficult due to differences in length of experimental duration. With respect to removal rates and number of exposure days for seeds, some examples from large-seeded Neotropical trees are: 65\% in Astrocaryum aculeatum, 30 days (Jorge \& Howe 2009); 83\% in Astrocaryum standleyanum, 8 days (Jansen et al. 2012); 80\% on average in Oenocarpus mapora, 6 days (Beckman \& MullerLandau 2007); and 100\% in Bertholletia excelsa, 2 days (Augaasen et al. 2010). Our observed removal rates for the Afrotropical $C$. oreophila is certainly comparable to these; however, our study sits at the higher-end removal rates, with some experimental plots experiencing complete seed depletion, at the end of — or even before—our 10 day trials. High removal rates by scatter-hoarders are important if they are to contribute appreciably to seed dispersal (Theimer 2005, Schupp 1993), 
but the nutrient rich seeds of $C$. oreophila also make it an attractive food source. Given our observed removal rates were more-or-less similar across habitats (core, edge, and forest fragments), habitat-specific differences in scatter-hoarder behavior will determine whether these mammals act as dispersers or predators.

Forest fragmentation and disturbance are often associated with higher rates of seed predation (Jorge \& Howe 2009, Forget et al. 1999, Aliyu et al. 2014). Indeed, the likelihood that scatterhoarders choose to immediately consume a seed (versus hoard and disperse it) is expected to be greater when food is scarce (Vander Wall \& Beck 2012, Augaasen et al. 2010, Jansen et al. 2004). Phenology records at Ngel Nyaki indicate very few moderate- and large-seeded species other than C. oreophila were fruiting during our study and that the onset of $C$. oreophila fruiting began after a period of potentially low food abundance (Fig. 1). The posterior probability means for hoarded seed proportions showed a negative trend from core, to edge, to forest fragments, across all four temporal replicates (Fig 3). It therefore appears that the decision of scatter-hoarding rodents to hoard seed might be more likely in less disturbed forest, regardless of the amount of food available.

While we predicted that the proportion of consumed seeds would increase from core, to edge, to forest fragments, this was strongly supported during Periods 2 and 3 only (Table 1). Such temporal shifts in the influence of habitat on rodents' decisions to immediately consume seeds appear to covary with shifts in seed availability. Habitat disturbance did not affect consumption rates immediately after an apparent seed shortage (Period 1) or when C. oreophila seeds were becoming scarce (Period 4), but did when C. oreophila seeds were relatively abundant over several weeks (Periods 2 and 3). This implies that seeds produced in the middle of high fruiting periods, and in less disturbed forest, are less prone to immediate consumption and might have a greater chance of being hoarded. We know from over 10 years of field observations at Ngel Nyaki that accumulation of $C$. oreophila seeds under parental trees has never been observed (H. Chapman, pers. comm.). This corroborates with the high removal rates measured in this study, further highlighting $C$. oreophila seed as an especially attractive food source that is unlikely to saturate granivores to a level where seeds go largely undetected. Consequently, in C. oreophila, all seeds are expected to encounter scatter-hoarding rodents, so ecological context will thus be exceedingly important in determining the overall benefit these mammals provide.

Our results are particularly relevant in understanding the importance and effectiveness of scatter-hoarding mammals as dispersal agents for large-seeded trees in anthropogenically disturbed landscapes. Most of our understanding about secondary dispersal in tropical forests comes from Neotropical studies, where evidence suggests scatter-hoarders may currently be the only dispersal agents for trees that have lost their primary dispersers (Forget 1996, Jansen et al. 2004, 2012). In the Afrotropics, it is apparent that defaunation of large-bodied frugivores correlates with stunted 
recruitment in dependent trees (Babweteera 2009, Babweteera et al. 2007, Babweteera \& Brown 2010, Thia et al. 2016). However, few empirical studies have investigated the role of scatterhoarders as dispersers of large-seeded trees, yet alone explicitly tested the conditionality of this mutualism (Aliyu et al. 2014, Nyiramana et al. 2011, Moupela et al. 2014, Rosin \& Poulsen 2017). Previous work we conducted at Ngel Nyaki illustrated how species-specific seed traits can be important in modulating habitat effects on seed fate (Aliyu et al. 2014). Rosin and Poulsen (2016) have also shown that seed size can be a strong predictor of which members of the granivore community will interact with particular tree taxa in a lowland Gabon forest. Certainly, while growing empirical works in the Afrotropics indicate that scatter-hoarders contribute highly to the secondary movement of seeds, long-term studies are required to determine the ultimate fates of these seeds (with respect to their dispersal distance, survival, and establishment into seedlings).

A caveat of this study is that despite recovering $\sim 66 \%$ of all seeds there were still a sizeable number of seeds whose fates remain unknown. We did not directly test hypotheses on the missing data, but our results evidenced that differences among habitats in missing data varied across temporal replicates (Fig. 3). Additionally, the actual amount of missing data also varied across temporal replicates (Fig. 2B). These habitat differences and temporal effects imply the ecological processes contributing to missing data might not be consistent across our study-though experimental error in recovering seed within the bounds of the study is also a contributing factor. Consequently, while we can provide assessment of how habitat effects (testing whether seed fates differ along a forest disturbance gradient) change across the fruiting season, we cannot assess the overall proportions of each seed fate. Indeed, missing data is a general problem in seed fate studies that requires the use of tracking technologies to truly remove all ambiguity in inferences (Hirsch et al. 2012).

One additional caveat is that we counted recovered loose threads as consumed instead of missing, which has the potential to inflate consumption rates. While it is possible that rodents may have bitten through the string and taken the seed elsewhere, or that the thread may have broken off the seed, neither scenario seems likely because: (1) preliminary data and prior work at Ngel Nyaki (Aliyu et al. 2014) suggests that scatter-hoarders are unfazed by threaded seeds; and (2) the thread was highly durable and pierced through the seed, so unless scatter-hoarders had selectively removed it, the seed would have to be gnawed through in order for the thread to become detached.

Rosin and Poulsen (2016) have made headway in the Afrotropics by combining telemetric tagging and camera traps to determine the dispersal distance, initials fates, and disperser species of Gambeya lacourtiana and Chrysophyllum lacourtiannum in a lowland Gabon forest. While it has been previously speculated that rats of the genus Cricetomys are likely one of the most important secondary dispersers of many large-seeded Afrotropical trees (Aliyu et al. 2014, Nyiramana et al. 
2011, Dutton et al. 2014, Moupela et al. 2014), Rosin and Poulsen infer the contrary. Their work suggests a greater predatory role of Cricetomys rats, while the African brush-tailed porcupine, Atherurus africanus, might be responsible for longer dispersal distances. Both these mammal species occur at our study site and camera traps have demonstrated their utilization of $C$. oreophila seed as food. Certainly, if Rosin and Poulsen's observations are translatable across African forests, some of our missing data may be attributed to larder-hoarded seed by Cricetomys rats and a small proportion to seed moved by A. africanus to distances beyond our searching limit. Future work at Ngel Nyaki is underway to understand the relative roles and dispersal services provided by these different rodent taxa.

In summary, this study indicates that scatter-hoarders may hoard more seeds in less disturbed forest, but difference among habitats might only be marginal if food availability alters the immediate decision of scatter-hoarders to consume (instead of hoard) seeds. Anthropogenic disturbance disrupts tropical forests in a multitude of ways through the manipulation of the physical environment, which ultimately has consequences for the abundance, diversity, and behavior of resident plants and animals. The declines in recruitment of large-seeded tree populations may lag behind the loss of their frugivore mutualists due to their long generation times. In developing models to predict tree species recruitment in the face of change, seed traits and food abundance are two key factors likely to influence a scatter-hoarder's strategy with regards to immediate consumption of seeds versus storing them for later consumption. Understanding the most likely scenarios that shift the relationship of scatter-hoarders from mutualists to predators will be necessary in predicting and managing recruitment of large-seeded trees in degraded landscapes.

\section{ACKNOWLEDGMENTS}

We thank the Taraba State Government for inviting us to work in Ngel Nyaki Forest Reserve, and the Nigerian Montane Forest Project for logistical help. This manuscript was improved by the helpful comments of two anonymous reviewers and suggestions by the editor. Financial support came from long-term supporters of the Nigerian Montane Forest Project: Chester Zoo (UK), CNOOK Nexen Nigeria, and the A. G. Leventis Foundation.

\section{DATA AVAILABILITY}

Data available from the Dryad Digital Repository: https://doi.org/10.5061/dryad.c377tq8 (Aliyu et al. 2018).

\section{LITERATURE CITED}

Adanu, J., S. Volker, and A. Fowler. 2010. Hunters, fire, cattle: Conservation challenges in eastern 
Nigeria with special reference to chimpanzess. In S. Volker and C. Ross (Eds.) Primates of Gashaka: Socioecology and Conservation in Nigeria’s Biodiversity Hotspot. pp. 74-77, Springer.

Agresti, W. W. 1986. New paradigms for software development: tutorial. IEEE Computer Society Press.

Aliyu, B. 2014. The interplay of habitat and seed size on the shift in species composition in a fragmented Afromontane forest landscape: Implications for the management of forest restoration. The University of Canterbury.

Aliyu, B., H. Adamu, E. Moltchanova, P. M. Forget, and H. Chapman. 2014. The interplay of habitat and seed type on scatterhoarding behavior in a fragmented Afromonate forest landscape. Biotropica 46: 264-267.

Aliyu, B., J. A. ThiA, E. Moltchanova, P-M. Forget, And H. M. Chapman. 2018. Data from: Forest disturbance and seasonal food availability influence a conditional seed dispersal mutualism. Dryad Digital Repository. doi:10.5061/dryad.c377tq8

Augaasen, T., C. A. Peres, R. Gribel, and P. Wegge. 2010. Seed dispersal of the Brazil nut tree (Bertholletia excelsa) by scatter-hoarding rodents in a central Amazonian forest. J. Trop. Ecol. 26: $251-262$.

Babweteera, F. 2009. Cordia millenii: on the risk of local extinction? Afr. J. Ecol. 47: 367-373. Babweteera, F., and N. Brown. 2010. Spatial patterns of tree recruitment in East African tropical forests that have lost their vertebrate seed dispersers. J. Trop. Ecol. 26: 193-203.

Babweteera, F., P. Savill, and N. Brown. 2007. Balanites wilsoniana: Regeneration with and without elephants. Biol. Conserv. 134: 40-47.

Beck, J., and H. Chapman. 2008. A population estimate of the Endangered chimpanzee Pan troglodytes vellerosus in a Nigerian montane forest: implications for conservation. Oryx 42 : $448-451$.

Beckman, N. G., and H. C. Muller-Landau. 2007. Differential effects of hunting on pre-dispersal seed predation and primary and secondary seed removal of two Neotropical tree species. Biotropica 39: 328-339.

Brewer, S. 2001. Predation and dispersal of large and small seeds of a tropical palm. Oikos 92: $245-255$.

Chapman, J. D., and H. M. Chapman. 2001. The forests of Taraba and Adamawa States, Nigeria. Department of Plant and Microbial Sciences, University of Canterbury, Christchurch.

Chauvet, S., and P. Forget. 2005. Edge effects on post-dispersal seed removal in a fragmented rain forest in French Guiana. J. Trop. Ecol. 21: 113-116.

Cramer, J. M., R. C. G. Mesquita, T. V. Bentos, B. Moser, and G. B. Williamson. 2007. Forest 
fragmentation reduces seed dispersal of Duckeodendron cestroides, a Central Amazon endemic. Biotropica 39: 709-718.

Debroux, L. 1998. L'aménagement des forêts tropicales fondé sur la gestion des populations d'arbres: l'exemple du moabi (Baillonella toxisperma Pierre) dans la forêt du Dja, Cameroun.

Dutton, P. E., H. M. Chapman, and E. Moltchanova. 2014. Secondary removal of seeds dispersed by chimpanzees in a Nigerian montane forest. Afr. J. Ecol. 52: 438-447.

Forget, P.-M. 1990. Seed-dispersal of Vouacapoua americana (Caesalpiniaceae) by caviomorph rodents in French Guiana. J. Trop. Ecol. 6: 459-468.

Forget, P.-M. 1996. Removal of seeds of Carapa procera (Meliaceae) by rodents and their fate in rainforest in French Guiana. J. Trop. Ecol. 12: 751-761.

Forget, P.-M., and L. Cuijpers. 2008. Survival and Scatterhoarding of Frugivores-Dispersed Seeds as a Function of Forest Disturbance. Biotropica 40: 380-385.

Forget, P.-M., K. Kitajima, and R. B. Foster. 1999. Pre- and post-dispersal seed predation in Tachigali versicolor (Caesalpiniaceae): effects of timing of fruiting and variation among trees. J. Trop. Ecol. 15: 61-81.

Forget, P., D. Hammond, and T. Milleron. 2002. Seasonality of Fruiting and Food Hoarding by Rodents in Neotropical Forests: Consequences for Seed Dispersal and Seedling Recruitment. In D. J. Levey, W. R. Silva, and M. Galetti (Eds.) Seed dispersal and frugivory: ecology, evolution and conservation. pp. 241-253, CABI Publishing, Wallingford, Oxfordshire, UK.

Forget, P., T. Milleron, and F. Feer. 1998. Patterns in post-dispersal seed removal by neotropical rodents and seed fate in relation to seed size. In D. M. Newbery, H. T. T. Prins, and N. D. Brown (Eds.) Dynamics of Tropical Communities. pp. 25-49, Blackwell Science, Cambridge, UK.

Guimaraes Jr., P. R., M. Galetti, and P. Jordano. 2008. Seed dispersal anachronisms: Rethinking the fruits extinct megafauna ate. PLoS One 3: e1754.

Hirsch, B., R. Kays, and P. Jansen. 2012. A telemetric thread tag for tracking seed dispersal by scatter-hoarding rodents. Plant Ecol. 213: 933-943.

Hirsch, B., R. Kays, V. Pereira, and P. Jansen. 2012. Directed seed dispersal towards areas with low conspecific tree density by a scatter-hoarding rodent. Ecol. Lett. 5: 1423-1429.

Holl, K., and M. Lulow. 1997. Effects of Species, Habitat, and Distance from Edge on Postdispersal Seed Predation in a Tropical Rainforest. Biotropica 29: 459-468.

Jansen, P. A., F. Bongers, and L. Hemerik. 2004. Seed mass and mast seeding enhance dispersal by a neotropical scatter-hoarding rodent. Ecol. Monogr. 74: 569-589.

Jansen, P. A., B. T. Hirsch, W. J. Emsens, V. Zamora-Gutierrez, M. Wikelski, and R. Kays. 2012. Thieving rodents as substitute dispersers of megafaunal seeds. Proc. Natl. Acad. Sci. 109:

This article is protected by copyright. All rights reserved 
$12610-12615$.

Jorge, M., and H. Howe. 2009. Can forest fragmentation disrupt a conditional mutualism? A case from central Amazon. Oecologia 161: 709-718.

Kenfack, D. 2011. A Synoptic Revision of Carapa (Meliaceae). Harvard Pap. Bot. 16: 171-231.

Matthesius, A., H. Chapman, and D. Kelly. 2011. Testing for Janzen-Connell effects in a West African Montane forest. Biotropica 43: 77-83.

Moupela, C., J.L. Doucet, K. Daïnou, N. Tagg, N. Bourland, and C. Vermeulen. 2014. Dispersal and predation of diaspores of Coula edulis Baill. in an evergreen forest of Gabon. Afr. J. Ecol. 52: 88-96.

Nyiramana, A., I. Mendoza, B. A. Kaplin, and P.-M. Forget. 2011. Evidence for seed dispersal by rodents in tropical montane forest in Africa. Biotropica 43: 654-657.

Pinto, S. R. R., A. M. M. Santos, and M. Tabarelli. 2009. Seed predation by rodents and safe sites for large-seeded trees in a fragment of the Brazilian Atlantic forest. Brazilian J. Biol. 69: 76371.

R Core Team 2016. R: A language and environment for statistical computing. Available at: http://www.r-project.org.

Ripple, W. J., K. Abernethy, M. G. Betts, G. Chapron, R. Dirzo, M. Galetti, T. Levi, P. A. Lindsey, D. W. Macdonald, B. Machovina, T. M. Newsome, C. A. Peres, A. D. Wallach, C. Wolf, and H. Young. 2016. Bushmeat hunting and extinction risk to the world's mammals. R. Soc. Open Sci. 3: 160498.

Rosin, C., and J. R. Poulsen. 2017. Telemetric tracking of scatterhoarding and seed fate in a Central African forest. Biotropica 49: 170-176.

Schupp, E. W. 1993. Quantity, quality and the effectiveness of seed dispersal by animals. Vegetatio 108: 15-29.

Sturtz, S., Ligges, U., Gelman, A. 2005. R2WinBUGS: A Package for Running WinBUGS from R. J. Stat. Softw. 12: 1-6.

Theimer, T. C. 2005. Rodent scatterhoarders as conditional mutualists. In P.-M. Forget, J. E. Lambert, P. E. Hulme, and S. B. Vander Wall (Eds.) Seed Fate: Predation, Dispersal, and Seedling Establishment. pp. 283-295, CABI Publishing, Cambridge, MA, USA.

Thia, J. A., M. L. Hale, D. B. Stouffer, and H. M. Chapman. 2016. Limited dispersal into appropriate microhabitats likely explains recruitment failure in a chimpanzee-dependent tree species. Afr. J. Ecol. 54.

Thia, J. A. Y. W. 2014. The Plight of Trees in Disturbed Forest: Conservation of Montane Trees, Nigeria. University of Canterbury.

Thornton, D. H., L. C. Branch, and M. E. Sunquist. 2012. Response of large galliforms and 
tinamous (Cracidae, Phasianidae, Tinamidae) to habitat loss and fragmentation in northern Guatamala. Oryx 46: 567-576.

Vander Wall, S. B. 2010. How plants manipulate the scatter-hoarding behaviour of seed-dispersing animals. Philos. Trans. R. Soc. B Biol. Sci. 365: 989-997.

Vander Wall, S. B., and M. Beck. 2012. A comparison of frugivory and scatter-hoarding seeddispersal syndromes. Bot. Rev. 78: 10-31.

Vander Wall, S., K. Kuhn, and M. Beck. 2005. Seed removal, seed predation, and secondary dispersal. Ecology 86: 801-806.

Wang, B., and J. Chen. 2009. Seed size, more than nutrient or tannin content, affects seed caching behavior of a common genus of Old World rodents. Ecology 90: 3023-3032.

Wang, B., C. X. Ye, C. H. Cannon, and J. Chen. 2013. Dissecting the decision making process of scatter-hoarding rodents. Oikos 122: 1027-1034.

\section{FIGURES AND TABLES}

FIGURE 1. Fruiting phenology of 15 moderate- and large-seeded tree species expected to be potential food sources of large granivorous rodents at Ngel Nyaki Forest Reserve. Trees occur along monthly-monitored transects and the number of trees with mature fruits are illustrated for each month. Fruiting of Carapa oreophila is represented by the thick black line and black dots. The occurrence of temporal replicate periods used in this study are indicated: Period $1=$ 18-28 August (P1); Period $2=5-15$ September (P2); Period $3=1828$ September (P3); Period $4=2-12$ October (P3).

FIGURE 2. Posterior mean probabilities $(P)$ of a Carapa oreophila seed being consumed, hoarded, or missing, with corresponding 95\% Bayesian credible intervals (CIs): (a) averages for habitats across temporal replicates $(\mathrm{COR}=$ core forest; $\mathrm{EDG}=$ edge forest; $\mathrm{FRG}=$ forest fragments); and (b) averages for temporal replicates across habitats (Period 1 = 18-28 August; Period 2 = 5-15 September; Period $3=18-28$ September; Period 4 =2-12 October).

FIGURE 3. Posterior mean probabilities $(P)$ and 95\% Bayesian credible intervals (CIs) for each Carapa oreophila seed fate (consumed $=$ top panel; hoarded $=$ middle panel; missing $=$ bottom panel) by temporally replicated periods (Period $1=18-28$ August; Period 2 $=5-15$ September; 
Period $3=18-28$ September; Period $4=2-12$ October) and habitat (COR = core forest; $E D G=$ edge forest; FRG = fragment forest).

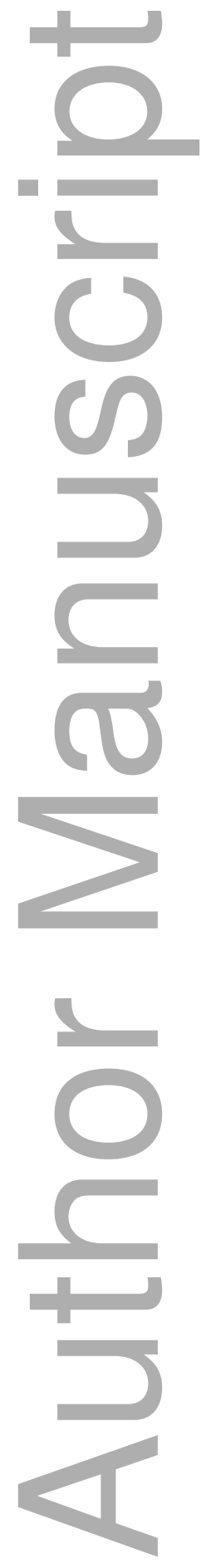

This article is protected by copyright. All rights reserved 
TABLE 1. Posterior probability support for hypotheses regarding the seed fates (consumed or hoarded) of Carapa oreophila in different forest habitats (COR = core forest; $E D G=$ edge forest; $\mathrm{FRG}=$ fragment forest). Inequality statements describe the direction of our hypotheses, which were tested in four temporal replicates (Periods 1-4) during the peak fruiting season to determine temporal variability in habitat effects.

\begin{tabular}{lll}
\hline Temporal replicate & Consumed & Hoarded \\
& COR < EDG < FRG & COR > EDG > FRG \\
\hline Period 1: 18-28 Aug & 0.0326 & 0.9886 \\
Period 2: 5-15 Sep & 0.9966 & 0.9840 \\
Period 3: 18-28 Sep & 0.9098 & 0.9800 \\
Period 4: 2-12 Oct & 0.1066 & 0.7034 \\
\hline
\end{tabular}




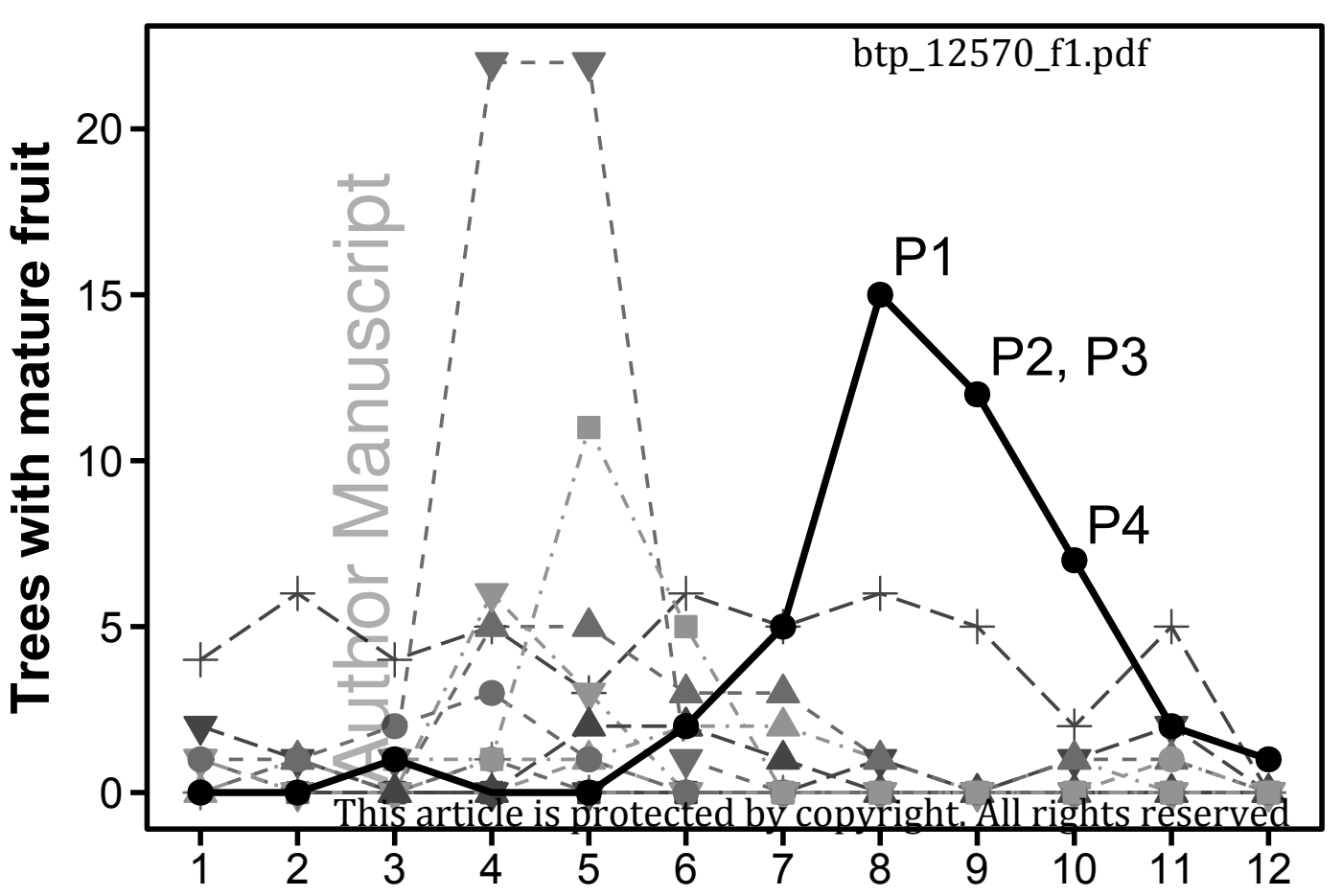

+- Anthocleista vogelii

$\checkmark$ Anthonotha noldeae

- Beilschmiedia mannii

- Carapa oreophyla

- Chionanthus africanus

$\checkmark$ - Entandrophragma angolense

- Garcinia smeathmannii

- Isolona deightonii

- Khaya grandifoliola

- Millettia barteri

+ Parkia filicoidea

- Pouteria altissima

- Santiria trimera

- Symphonia globulifera

-. Syzygium guineense

\section{Month}



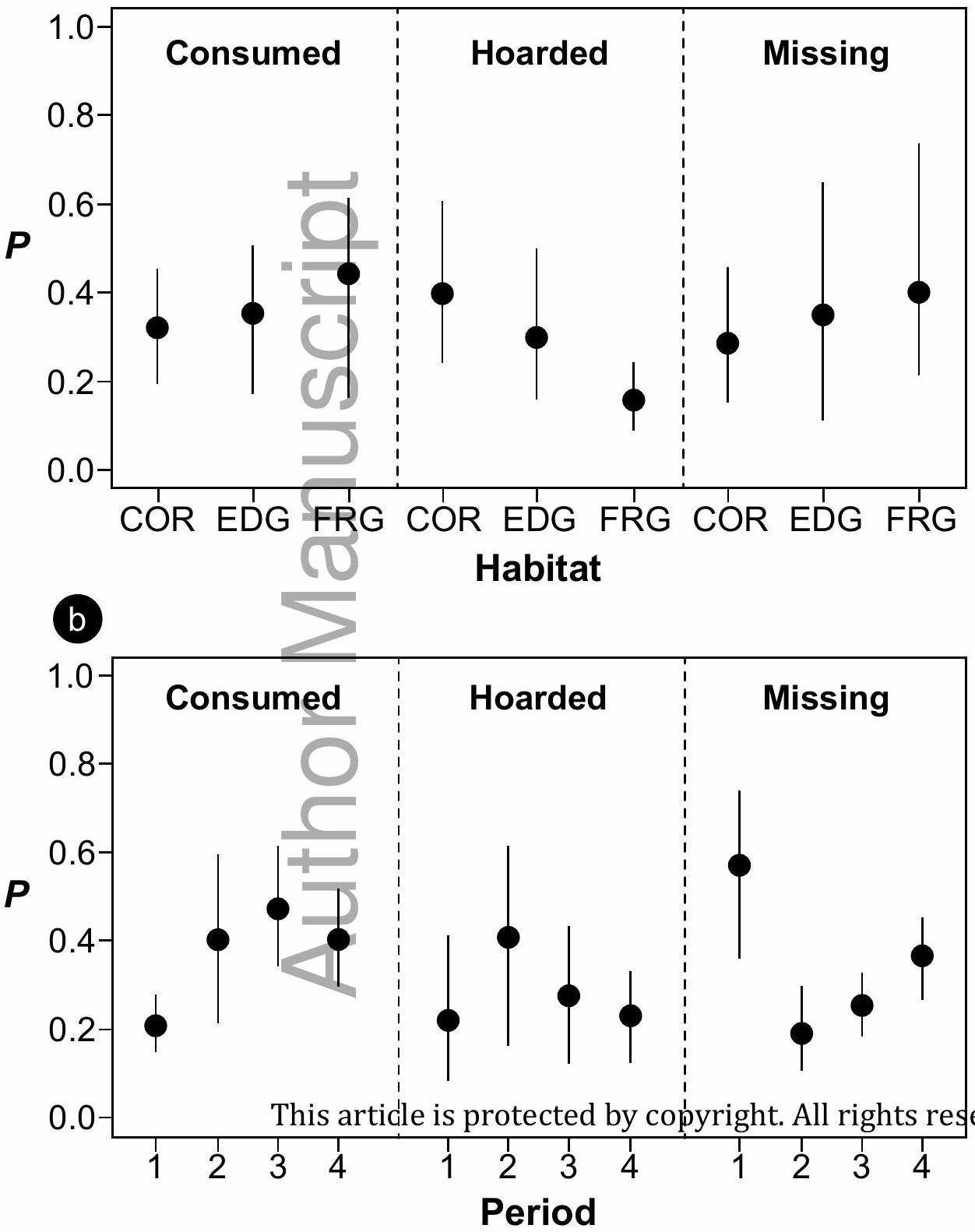
Temporal replicate
btp_125\%_\$3.pd1

Period 1 Period $2 \quad$ Period 3

Period 4

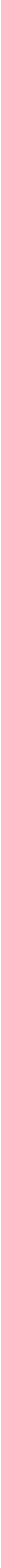




\section{University Library}

\section{- M M N E R VA A gateway to Melbourne's research publications}

Minerva Access is the Institutional Repository of The University of Melbourne

Author/s:

Aliyu, B;Thia, JA;Moltchanova, E;Forget, P-M;Chapman, HM

Title:

Forest disturbance and seasonal food availability influence a conditional seed dispersal mutualism

Date:

2018-09-01

Citation:

Aliyu, B., Thia, J. A., Moltchanova, E., Forget, P. -M. \& Chapman, H. M. (2018). Forest disturbance and seasonal food availability influence a conditional seed dispersal mutualism. Biotropica, 50 (5), pp.750-757. https://doi.org/10.1111/btp.12570.

Persistent Link:

http://hdl.handle.net/11343/285158 